\title{
Marital adjustment in the context of female breast cancer: A systematic review
}

Tânia Brandão ${ }^{1}$, Juliana Pedro ${ }^{1}$, Nuno Nunes ${ }^{1}$, Mariana V. Martins ${ }^{1}$, Maria Emília Costa $^{1}$, \& Paula Mena Matos ${ }^{1}$

${ }^{1}$ Faculty of Psychology and Education Sciences, University of Porto, Portugal; Center for Psychology at University of Porto, Portugal.

*Corresponding author: Paula Mena Matos - Faculty of Psychology and Education Sciences, University of Porto, Portugal; Center for Psychology at University of Porto. Email: pmmatos@fpce.up.pt

Funding: This work was funded by the Portuguese Foundation for Science and Technology (CPUP: UID/PSI/00050/2013; FEDER/COMPETE2020 POCI-01-0145-FEDER-007294; and a PhD scholarship granted to the first author, SFRH/BD/84436/2012).

Please Note: This is the author's version of the manuscript accepted for publication in PsychoOncology. Changes resulting from the publishing process, namely editorial editing, corrections, final formatting for publication, and other modifications resulting from quality control mechanisms may have been subsequently added.

A definitive version was subsequently published as: Brandão, T., Pedro, J., Nunes, N., Veloso, M. M., Costa, M. E., \& Matos, P. M. (2017). Marital adjustment in the context of female breast cancer: A systematic review. Psycho-oncology, 26, 2019-2029. Doi: 10.1002/pon.4432 


\begin{abstract}
Objective: Breast cancer (BC) diagnosis and subsequent treatments present significant challenges and distress for both patients and their partners. This can lead to difficulties in marital relationships and, consequently, decreases in marital adjustment and psychosocial adaptation to $\mathrm{BC}$ for both partners. Our objective was to systematically review studies assessing marital adjustment in the context of female BC to understand which factors are associated with marital adjustment in both patients and partners, and characterize the measures employed to assess marital adjustment within these studies.
\end{abstract}

Methods: This systematic review was conducted in accordance with PRISMA guidelines. English, peer-reviewed articles exploring factors associated with marital adjustment in the context of female $\mathrm{BC}$ were considered for inclusion.

Results: Fourteen studies were included. Results evidenced that psychosocial variables play an important role on marital adjustment. Specifically, open and constructive communication, more social support, and supportive dyadic coping were found to be associated with higher levels of marital adjustment. Other variables such as self-efficacy, sexual functioning, and psychological adjustment were also positively associated with marital adjustment.

Conclusions: Most studies evidenced an association between psychosocial variables and marital adjustment for both women and their partners. Some important dimensions such as communication patterns, coping strategies, and social support dynamics were identified as potential targets for psychological interventions. Some variables, however, were explored only in a few studies which limit our conclusions. Future studies should explore the role these variables and other relational and emotional variables play in promoting marital adjustment after BC.

Keywords: systematic review; breast cancer; marital adjustment; couple intervention; oncology; 


\section{Background}

Recent epidemiological data estimated that, in 2012, around 464,000 women were diagnosed with breast cancer (BC) and around 131,000 women died due to this disease in Europe ${ }^{1}$. Cancer is now recognized as a "we disease ${ }^{2}$ ". Diagnosis and subsequent treatments can generate challenges and distressing consequences that may persist over time, not only in patients but also their intimate partners and the relationship ${ }^{2}$. Women involved in a romantic relationship usually identify their partners as their main source of support ${ }^{3,4}$. Partners, however, may not always respond in a helpful and supportive way because they have to simultaneously deal with their own levels of psychological distress and difficulties in marital relationship ${ }^{5}$. Both patients and partners experience very similar reactions to BC diagnosis such as depression, anxiety, fear, and decreased quality of life ${ }^{6-10}$.

It is now recognized that marital adjustment, defined as "the process by which married couples attain mutual gratification and achieve common goals while maintaining an appropriate degree of individuality"11 [p.623] and commonly designed as marital satisfaction, marital quality or dyadic adjustment ${ }^{12}$, plays a crucial role for the health and psychological well-being of individuals. For instance, higher levels of marital adjustment have been associated with better physical health (including lower risk of mortality and cardiovascular reactivity) and higher levels of psychological well-being ${ }^{13,14}$. This pattern is also evident for other chronic diseases such as infertility ${ }^{15}$, chronic obstructive pulmonary disease ${ }^{16}$, and long-term hemodialysis ${ }^{17}$.

In the specific context of $\mathrm{BC}$ marital adjustment also emerges as an important factor for explaining psychological adaptation for both women and their partners. For women, higher levels of marital adjustment appear to be associated with better emotional adjustment, sexual functioning, quality of life, and body image ${ }^{18-21}$. Besides psychological maladjustment, a poor marital adjustment can also lead to slowed recovery trajectories and poor physical outcomes ${ }^{22}$. Studies also evidenced that for partners of $\mathrm{BC}$ women, better marital adjustment tends to be associated with lower levels of distress, few role problems, and higher levels of psychological well-being ${ }^{23-25}$.

Thus, it is important to explore and understand the factors that may contribute to differences in marital adjustment after a BC diagnosis. Couples do not respond to cancer in the same way. Some couples may have the necessary resources to cope with cancer, being able to maintain closeness or even to become closer and improve their marital relationship. Others may not possess the emotional resources required to deal effectively with this stressful event ${ }^{26-28}$.

The identification of factors that may contribute to differences in marital adjustment after BC diagnosis will help to identify individuals or couples that are at greater risk for psychological distress 
and refer them to adequate psychological support. On the other hand, given preliminary evidence about the possible benefits of couple-based interventions ${ }^{29}$, it will facilitate the identification of intervention targets for improving psychosocial care to couples facing $\mathrm{BC}$. The present systematic review aims to accomplish two main objectives: (1) to identify which factors (including demographic, disease-related and psychosocial factors) have been associated with marital adjustment in both patients and their partners, and (2) to identify and describe which measures have been employed to assess marital adjustment in the context of BC. Because BC can impact marital adjustment, and both patients and their partners can experience multiple changes in roles and responsibilities besides difficulties in communication, intimacy, and sexual issues ${ }^{30}$, it is important to understand which dimensions have been used to assess marital adjustment within this specific context. To our knowledge, this is the first systematic review addressing this topic.

\section{Methods}

This systematic review was performed according to PRISMA (Preferred Reporting Items for Systematic Reviews and Meta-Analyses) guidelines ${ }^{31}$

\section{Eligibility criteria}

Studies were included in this systematic review if they (1) included female BC patients and/or their partners (same-sex partners were not excluded); (2) assessed marital adjustment as a primary outcome; (3) evaluated factors associated with marital adjustment; (4) were published in English and in a peer-reviewed journal. Literature/systematic reviews, books/book chapters, unpublished articles and doctoral theses, commentaries, abstracts of conferences and congresses, case-reports, and qualitative studies were excluded.

\section{Search strategy}

Database searches were conducted from inception to March 2016 in different online healthrelated databases, including Academic Search Complete, CINAHL plus, ERIC, MedicLatina, MEDLINE, PsycARTICLES, PsycCRITIQUES, Psychology and Behavioral Sciences Collection, and PsycINFO. Searches in these databases were supplemented by additional manual searching in Google. The key search terms used were: breast cancer OR mastectomy OR breast neoplasm AND 
marital satisfaction OR marital relationship OR marital quality OR marital adjustment OR marital distress OR relationship satisfaction OR couple relationship OR marital interaction OR couple interaction OR couple adjustment $\mathrm{OR}$ couple satisfaction $\mathrm{OR}$ dyadic adjustment.

\section{Study selection}

After duplicates were removed, titles and abstracts were reviewed independently by two investigators to identify potentially relevant studies meeting inclusion criteria. Disagreements between reviewers about studies' eligibility were resolved by consensus.

\section{Data extraction and quality assessment}

The following information about the included studies was extracted: study objectives, participants, design, measure used to assess marital adjustment, and main findings. The quality assessment of the included studies was conducted by two reviewers independently and was performed according to the Strengthening the Reporting of Observational Studies in Epidemiology (STROBE) guidelines for cross-sectional and longitudinal studies ${ }^{32}$. Besides STROBE, and because marital adjustment is a relational construct, we also assessed the quality of studies according to their ability to capture intrapersonal and interpersonal influences of each partner to predict marital adjustment.

\section{Results}

\section{Description of studies}

A total of 789 studies were identified. From these, 398 were duplicates and were removed. After removal of duplicates, 391 studies remained and the titles and abstracts were carefully screened and evaluated. From these, 86 were retrieved for full-text screening. Most studies were excluded because they did not evaluate predictors of marital adjustment $(n=72)$. One study was excluded because the unit of analysis was the composite couple dyadic adjustment ${ }^{33}$ and hence due to interdependence of data no comparisons with the remaining studies could be done. A total of 14 studies were included in this review. The study selection process is presented in Figure 1.

Studies were published between 1993 and 2015. Of the 14 studies, eight used a longitudinal design and six used a cross-sectional design (three from the eight longitudinal studies performed also 
cross-sectional analyses). For the longitudinal studies, data collection ranged from baseline to 12 months $(M=10$ months; $S D=1.96)$. Most studies were conducted in the USA $(n=9 ; 64 \%)$ but there was a wide variety of other countries. Studies included in their samples couples $(n=7 ; 50 \%)$, patients $(n=6 ; 40 \%)$, or partners only $(n=1)$. Furthermore, three studies $(21 \%)$ included comparison groups of women or couples not facing BC. Sample sizes varied greatly, ranging from 40 to 538 in studies including couples; 95 to 219 in studies focusing exclusively on patients; only one study focused exclusively on partners $(\mathrm{N}=100)$. Data were gathered from 1550 women and 1045 partners, with a mean age of 51 years $(\mathrm{SD}=3.17)$ for women, and 54 years $(\mathrm{SD}=3.51)$ for partners. The mean of relationship length was 25 years $(\mathrm{SD}=2.53)$. Regarding statistical procedures, eleven studies used regression analysis and four studies used multilevel models analysis (one presented both types of analyses). Regarding medical information, 12 studies were conducted in early stage BC and 2 studies in women with both early and advanced stages. Only 6 studies provided information regarding time since diagnosis $(M=16.32$ months; $\mathrm{SD}=20.05)$. Three studies reported data from time since surgery $(\mathrm{M}=4.5$ months; $\mathrm{SD}=5.24)$. A detailed description of the 14 studies is presented in supplemental data STable 1.

\section{Quality assessment}

Results from the quality assessment are presented in supplemental data STable 2. It is important to note that none of the studies fulfilled all of the STROBE criteria and for some studies we could not apply some criteria. The scores ranged from $13 / 29(45 \%)^{34}$ to $22 / 24(92 \%)^{35}$. It was possible to identify that none of the studies described the efforts to address potential sources of bias, identified how the study size was arrived at, indicated the number of participants with missing data for each variable of interest, or described any sensitivity analyses. Only three studies explained how missing data were addressed. Few studies used a flow diagram to present data regarding number of participants, participation rates, and reasons for non-participation or drop-out.

None of the studies assessed predictors of marital adjustment using a dyadic approach.

\section{Factors associated with marital adjustment in patients}

Different demographic, disease-related, and psychosocial factors were found to be associated with marital adjustment (see Table 1). Demographic variables assessed were age (3 studies), years of 
marriage (2), socioeconomic status (1), family income (1), partner's age (1), and education (1). Disease-related variables included length of diagnosis (1), physical impairment (1), years after mastectomy (1), comorbidity (1), chemotherapy (1), affected lymph nodes (1), and surgery (1). From all these variables, only patient age was significantly associated with marital adjustment. In two studies, one cross-sectional and one longitudinal, being older was associated with higher marital adjustment for BC women ${ }^{36,37}$ (even when women with advanced stage were included). In one crosssectional study, however, age was not significantly related to marital adjustment ${ }^{34}$. It is important to note, however, that in this study the mean time since diagnosis was more than 4 years. None of the remaining variables were significantly associated with marital adjustment for patients.

Psychosocial variables included communication patterns (5), social support (5), psychological adjustment (4), dyadic coping (2), sexual functioning (1), self-efficacy (1), hope (1), optimism (1), self and partner's perspective taking (ie, empathy) (1), self and partner's perception of body image (1), intimacy (1), and illness demands (1). For early stage BC women, communication patterns were significantly associated with marital adjustment. On one hand, demand withdrawal communication, protective buffering (eg, deny fears or avoid negative experiences), and perceived partner canceroriented topic avoidance and husband's disengagement, were associated with lower marital adjustment $^{38-40}$. On the other hand, constructive communication and disclosure of opinions and feelings were associated with higher levels of marital adjustment ${ }^{41}$. In one study, communication assertiveness was associated with marital adjustment. Specifically, women who tended to not express their thoughts and feelings and experienced high levels of tension when doing so tended to present lower marital adjustment ${ }^{39}$. Mutual avoidance (ie, both partners avoiding discussions) was not significantly associated with marital adjustment ${ }^{41}$.

Social support was significantly associated with marital adjustment on early stage BC women in two longitudinal studies. More specifically, partner positive emotional involvement, and emotional, informational, and instrumental support from partner were associated with higher levels of marital adjustment. Lower levels of marital adjustment were associated with negative support (ie, arguing or criticizing) $)^{35,42}$. While patient constrains (i.e., patient perception of partner's avoidance or disinterest related to her cancer-related concerns) were associated with lower levels of marital adjustment, a significant association was not found for partner constrains (i.e., partner perception of own avoidance or disinterest $)^{43}$. Neither social support nor social quality of life were predictors of marital adjustment in two longitudinal studies, one including advanced stage $\mathrm{BC}$ women ${ }^{44,45}$ and the other including both early and advanced stage. 
Psychological adjustment was significantly associated with marital adjustment in two longitudinal studies with early stage BC women. Specifically, depressive symptoms were associated with lower marital adjustment, and higher psychological quality of life was associated with higher marital adjustment ${ }^{28,43}$. In other two cross-sectional studies, psychological distress (including partner psychological distress in one study) was not significantly associated with marital adjustment ${ }^{34,36}$.

Dyadic coping was also associated with marital adjustment. In a longitudinal study, patient common dyadic coping (ie, both partners participate in the coping process symmetrically) was a positive predictor of marital adjustment, while both patient and partner negative dyadic coping (ie, superficial or hostile support coping) were negative predictors ${ }^{37}$. Supportive and delegated coping strategies (ie, when one partner employs coping efforts in order to reduce the other partner's stress) were not significantly associated with marital adjustment ${ }^{37}$. Relational and sexual issues were associated with levels of marital adjustment in one longitudinal study ${ }^{35}$. Specifically, marital adjustment was positively predicted by frequency of sexual activity, perception of partner emotional involvement quality of the first sexual experience after the surgery, and partner's interest to initiate sexual activity. Moreover, positive perceptions regarding emotional involvement and sexual interest from partners were related to marital adjustment 12 months later, even after controlling for baseline marital adjustment.

Self-efficacy was also significantly associated with marital adjustment, with self-satisfaction and personal management being associated with higher marital adjustment, and difficulties in activity management (ie, ability to perform work as did before cancer) and affective management (ie, ability to manage anger and fear related to cancer) being associated with lower marital adjustment ${ }^{46}$. Hope was associated with marital adjustment. More hope was associated with higher levels of marital adjustment. Neither partner's hope nor patient's and partner's optimism were, however, significantly associated with marital adjustment ${ }^{36}$. In this case, the study included advanced stage BC women, which can have an impact on hope and optimism levels of participants.

Patient's and partner's self-perspective taking (ie, the cognitive tendency to put oneself in another person's place) were associated with marital adjustment. Patient's self-perspective taking and patient's perception of partner's perspective-taking were associated with higher levels of marital adjustment. Partner's perception of patient's perspective taking was associated with higher marital adjustment. Partner's self-perspective taking, however, was not significantly associated with marital adjustment ${ }^{34}$. Partners' perception of patients' body image characterized by higher body image concerns were associated with lower marital adjustment, but patients' body image concern was not significantly associated with marital adjustment ${ }^{34}$. Intimacy and experience of illness demands (ie, 
illness-related thoughts, concerns, and events experienced after BC diagnosis) were not significantly associated with marital adjustment ${ }^{28,45}$.

Two longitudinal studies found that baseline levels of marital adjustment predicted marital adjustment levels longitudinally ${ }^{37,41}$. In both studies, marital adjustment diminished significantly from baseline to 9 months ${ }^{41}$ and to 5 months follow-up ${ }^{37}$. In both studies, at follow-up the majority of women had finished their treatments or was doing hormonal therapy.

\section{Factors associated with marital adjustment in partners}

Demographic, disease-related, and psychosocial variables were associated with marital adjustment in partners (see Table 2). Demographic variables included age (2 studies), years of marriage (2), socioeconomic status (SES) (1), family income (1), and education (1). Disease-related variables included length of diagnosis (1), chemotherapy (1), physical impairment (1), years after mastectomy (1), comorbidity (1), affected lymph nodes (1), and surgery (1). From these, only chemotherapy and SES were significantly associated with marital adjustment as reported by partners $^{37,45}$. Specifically, absence of patient chemotherapy was associated with higher marital adjustment. Higher socioeconomic status was associated with lower marital adjustment.

Psychosocial variables included psychological adjustment (2), communication patterns (2), dyadic coping (1), social support (1), sexual factors (1), self and partner's perspective taking (1), and self and partner's perception of body image (1).

Psychological adjustment was associated with marital adjustment. Depression and psychological distress were associated with lower marital adjustment ${ }^{34,45}$. Communication patterns were also associated with marital adjustment. While demand withdrawal and disengagement communication were associated with lower marital adjustment, constructive communication was associated with higher marital adjustment ${ }^{40,41}$. Mutual avoidance communication was not significantly associated with marital adjustment ${ }^{41}$. This pattern was also evident in patients. Dyadic coping was also related to marital adjustment in one study. Specifically, patient's and partner's negative dyadic coping were associated with lower marital adjustment, and patient's and partner's common dyadic coping were associated with higher marital adjustment ${ }^{37}$. In the same study, supportive and delegated coping were not significantly associated with marital adjustment for $\operatorname{partners}^{37}$. 
Social support (in terms of patient's and partner's constrains) was not significantly associated with marital adjustment ${ }^{43}$. The same happened with sexual functioning factors ${ }^{47}$. Regarding selfperspective taking, for partners, only their own self-perspective taking was associated with marital adjustment. Patients' perception of partners' perspective-taking, wives' self-perspective taking, and wives' perception of husbands' perspective taking were not significantly related to marital adjustment. The same happened to partners' perception of wives' body appearance and wives' perception of their own body appearance ${ }^{34}$.

In two longitudinal studies baseline levels of marital satisfaction were significantly associated with marital adjustment levels in a second time, with higher marital adjustment at baseline being associated with higher marital adjustment later ${ }^{37,41}$. This pattern was also evident for patients.

\section{Measures}

All studies used self-report instruments. Half of the studies $(n=7 ; 50 \%)$ assessed marital adjustment using the Dyadic Adjustment Scale (DAS) ${ }^{48}$ that includes the following dimensions: dyadic consensus, dyadic satisfaction, dyadic cohesion, and affectional expression. Other instruments were used, namely the Marital Opinion Questionnaire (MOQ) ${ }^{49}$, a unidimensional scale, the Maudsley Marital Questionnaire (MMQ) ${ }^{50}$ that includes the following dimensions: marital adjustment, sexual adjustment, and general life adjustment, and the Locke-Wallace Marital Adjustment Test (MAT) ${ }^{51}$ a unidimensional scale. Overall, the instruments were reliable, presenting good internal consistency (Cronbach's $\alpha$ ranged from .73 to .96, in the eleven studies that reported information regarding scales' internal consistency). These instruments are widely used to in the larger field of romantic relationship.

Fewer studies ( $\mathrm{n}=4 ; 29 \%$ ) assessed marital adjustment using one-single item/question (eg, "How do you rate the quality of your relationship"; "Choose a number from 0 to 7 that best describes your current degree of happiness in your relationship").

\section{Discussion}

The important role of marital adjustment, specifically in couples' adaptation to $\mathrm{BC}$, is widely recognized. Thus, this systematic review aimed to explore the demographic, disease-related, and psychosocial factors associated with marital adjustment for patients and their partners, and to identify and describe which measures have been used to assess marital adjustment in the context of BC. To 
our knowledge, this is the first review addressing these questions. As expected, different demographic, medical, and psychosocial variables were found to be associated with marital adjustment for both patients and their partners.

Regarding the quality of the included studies, it was possible to conclude that, except for one ${ }^{34}$, all studies meet at least $50 \%$ of the STROBE criteria, and two exceeded $80 \%$ of these criteria ${ }^{35,39}$. The moderate quality found in the included studies is in accordance with other systematic reviews conducted in similar fields (e.g., dyadic coping and marital relationship in couples coping with cancer $^{52}$ or marital relationship in infertility context ${ }^{53}$ ). Nevertheless, this indicates the need of conducting studies with greater quality, namely in terms of design (eg, sample size power analyses, longitudinal designs, inclusion of control groups) and data analyses (eg, explanation of how missing data is addressed).

\section{Factors associated with marital adjustment for patients and partners}

Regarding demographic and disease-related variables, age was the only variable significantly associated with marital adjustment in patients, with two studies suggesting older women to be more adjusted to their marital relationship after BC diagnosis. One possible explanation for this relationship between age and marital adjustment can be related to the fact that older women/older couples are in a different developmental stage with a closer and stronger relationship which can buffer the impact of BC in their marital adjustment. Length of relationship was not a significant predictor neither for women nor for their partners. Studies conducted in the larger field of psychology, however, are inconsistent. While some studies have found that women in long-term relationships presented lower levels of marital quality and that marital quality tend to diminish over time $\mathrm{s}^{54,55}$, other studies have found that marital quality is high in long-term relationships ${ }^{56}$. This inconsistency, however, is not a surprise since many other variables may play a role on marital adjustment over time.

Also, BC diagnosis poses greater challenges for young women in dimensions that might be no longer as relevant to older women (e.g., chemotherapy-induced menopause, fertility issues) ${ }^{57}$. BC treatments are usually more aggressive for young women which usually lead to higher levels of psychological distress ${ }^{57,58}$. This can impact the couple relationship and, consequently, marital adjustment.

In fact, psychological distress was also a significant predictor of marital adjustment evidencing that women who presented more depressive symptoms and higher levels of psychological distress presented lower levels of marital adjustment. Psychological distress can impact marital 
relationship by creating conflicts for couples and difficulting the provision of social support. For this reason, the possible mediating role of psychological distress in the association between age and marital adjustment should be analyzed in future studies. Since younger couples may be at greater risk for developing marital maladjustment, it is important to refer them to adequate psychological support after $\mathrm{BC}$ diagnosis to promote marital adjustment and couple adaptation. Considering the role psychological distress plays in marital adjustment for both women and their partners, couples should be screened for psychological distress after diagnosis and monitored during treatments and survivorship.

In terms of psychosocial variables, the results were very similar for both patients and their partners (except for social support and sexual functioning, as discussed below). Communications patterns were clearly linked to marital adjustment for both members of the couple. Couples were more adjusted when they used more adaptive communication strategies (eg, constructive communication) and less non-adaptive communication strategies (eg, demand-withdrawal or disengagement). Moreover, for women, protective buffering and perception of partner's topic avoidance were also associated with lower marital adjustment, while partner's disclosure of opinions and assertiveness was related to higher marital adjustment. This is in accordance with previous research on marital adjustment, in which communication patterns influence marital adjustment in romantic relationships ${ }^{59,60}$. These results highlighted the importance of improving communication styles of couples, promoting an open and constructive communication, the expression of thoughts, emotions, fears, and opinions, especially regarding cancer experience, in order to increase emotional closeness between members of the couple and improve marital relationship and adjustment ${ }^{61}$.

Dyadic coping was also associated with marital adjustment for both women and their partners. Since BC is considered a dyadic stressor, when both members of the couple take a "we" approach and work together to cope with this experience, they become more adjusted in their relationship. In fact, a more negative dyadic coping characterized by distance, criticism, or diminution of patients' need can pose specific challenges for the marital adjustment and contribute to increase the psychological distress experienced by women and their partners. On the contrary, a more positive or common dyadic coping can bring couples together and help them to develop the resources they need to better cope with $\mathrm{BC}^{37}$. These findings regarding the association between dyadic coping and marital adjustment are consistent with studies in the context of other cancer types (eg, prostate cancer) ${ }^{62}$ and studies outside of $\mathrm{BC}$ context ${ }^{63}$. It seems that dyadic coping plays an important role on relationship satisfaction for both women and their partners regardless of which partner is diagnosed. This was suggested by Regan and colleagues ${ }^{62}$, that did not confirm their hypothesis on a differential impact of dyadic coping for patients and wives. 
As expected, social support was also a significant factor associated with marital adjustment but only for women. The important role of social support in $\mathrm{BC}$ adaptation as well as in marital adjustment in the larger field is widely recognized ${ }^{64}$. It is important to note that negative support was associated with lower marital adjustment, suggesting that not all type of provided support is adequate and more important than the amount of support is the quality of support. For partners, however, this relationship was not evident. It is important to note that only one study explored this relationship.

Finally, baseline levels were related to marital adjustment across studies for both women and their partners (with follow-up ranging from 5 to 9 months). This highlighted the need to assess marital adjustment after BC diagnosis in order to identify couples who report lower initial levels of marital adjustment or initial marital difficulties and, for this reason, could benefit more from psychosocial support after BC diagnosis.

From the 14 included studies, it was possible to identify four different self-report measures to assess marital adjustment in BC. The Dyadic Adjustment Scale was the most common used scale to assess marital adjustment. It is a scale that has been widely used to assess couples' adjustment and the relationship quality among couples. It includes four dimensions: dyadic consensus, dyadic satisfaction, dyadic cohesion, and affective expression.

The measures found in this systematic review are also used in the larger field of psychology ${ }^{66}$. In a systematic review that explored relationship adjustment in the context of other chronic stressors, the DAS and the MAT were also the most common used scales to assess marital adjustment and presented also good psychometric properties $^{53}$. In the context of cancer, in a systematic review exploring the associations between dyadic coping and marital relationship, the DAS was also the most frequently used scale ${ }^{52}$.

The measures used in the included studies presented adequate internal consistency, although some studies did not report psychometric data regarding the instruments. Also, studies did not explore the factorial structure of the measures in this context. It should not be excluded the possibility of marital adjustment in face of $\mathrm{BC}$ be better conceptualized and assessed by other dimensions. It is also important to note that some studies assessed marital adjustment using only 1-item question. It would be important to collect more information regarding these or other measures that could be reliably used in the context of $\mathrm{BC}$. In a recent meta-analysis of measures used to assess marital adjustment the Kansas Marital Satisfaction Scale was considered, from a reliability perspective, the strongest measure to assess marital adjustment in the larger field of psychology. ${ }^{66}$ It would be important to explore if this measure could be a valid and strong measure to use in the context of BC. 
It is important to note that all studies relied only on self-report measures. Since self-report questionnaires are vulnerable to bias (eg, social desirability), future studies should use other type of measures to assess marital adjustment in the context of BC such as behavioral observation tasks or clinical interviews.

\section{Limitations of the study and future research}

This review presents some limitations that should be noted. First, there is the risk of reporting bias since some important studies may not be included for a wide range of reasons (eg, linguistic constrains; studies may not be published in identifiable resources or may not be published because did not find significant results). In fact, only 14 studies were found. This demonstrates that the exploration of factors associated with marital adjustment in the context of BC is understudied. Moreover, some dimensions were explored only by few studies (eg, socioeconomic status, perspective taking, sexual functioning). For this reason, caution is needed in interpreting the results and drawing conclusions. Also, this highlights the need of further research analyzing marital adjustment risk and protective factors for couples facing $\mathrm{BC}$, with a focus on these and other unexplored dimensions.

Second, although many studies used a longitudinal design, the results obtained in this systematic review are limited because: (1) the quality of the included studies, as determined by STROBE guidelines, was moderate; (2) only three studies used a comparison control group, and only one of them explored a model of association between the different factors and marital adjustment for both patients and controls; (3) all studies explored factors associated with marital adjustment separately for patients and their partners (with the exception of one study that used the couple as the unit of analyses but was excluded as justified previously) leaving unexplored the interpersonal and intrapersonal influences involved in marital adjustment; (4) the majority of studies did not validate neither assess the psychometric properties of the measures used; some studies assessed marital adjustment with only 1-item question which can be quite limited, for this reason results should be interpreted with caution; (5) psychosocial factors associated with marital adjustment were assessed with different measures, which can contribute to inconsistency in results; and (6) our conclusions regarding measures used to assess $\mathrm{BC}$ marital adjustment are limited given that we only included studies conceptualizing marital adjustment as an outcome; hence, this review cannot give a full picture of all marital adjustment measures used within the context of BC. 
To improve knowledge of marital adjustment in the context of $\mathrm{BC}$, future studies should include larger samples and have longitudinal and dyadic designs to identify risk and protective factors predictive of later marital adjustment, and follow-ups able to explore marital adjustment trajectories at different stages of the disease. Additionally, different methods to assess marital adjustment should be used besides self-report measures; if using self-report measures, a more detailed analyze should be performed in terms of psychometric properties. Finally, future studies should employ more sophisticated data analytic approaches should be employed in order to capture intra and interpersonal effects between partners and accounts for dependencies between partners (eg, Actor-Partner Independence Model) ${ }^{67}$.

\section{Clinical implications}

In this review, it was possible to identify some potential protective and risk factors that can impact marital adjustment in couples coping with BC. This review results are of high importance for clinicians who work with BC women and their partners. First, some sociodemographic and diseaserelated factors were found to be associated with marital adjustment. These findings suggest that younger women and partners whose women underwent chemotherapy might be at greater risk for marital impairment, and hence could benefit from psychosocial support after BC diagnosis to prevent marital distress. Additionally, specific dimensions emerged as potential intervention targets for women and for partners. Because social support was positively associated with marital adjustment in patients, BC women could benefit from being included in group therapy with a social support focus (eg, supportive-expressive group therapy $)^{68}$. Both for women and partners, communication patterns and coping strategies were associated with marital adjustment. This suggests that psychologists and counselors should promote the development of more adequate communication patterns within a supportive context and more effective or adaptive coping strategies. In fact, some specific programs aiming to train communication skills and coping strategies have been successfully employed to promote marital adjustment in other stressful conditions such as infertility ${ }^{69}$ or osteoarthritis $^{70}$.

Although future studies are needed to explore marital adjustment in terms of dyadic functioning, the results presented here seem to suggest that couple-based interventions may be beneficial for improving marital adjustment of couples facing BC. In fact, some reviews have suggested that intervening at a couple level can be fruitful ${ }^{29,71}$. However, more studies are needed to explore these benefits since evidence is not compelling enough. 
In sum, our results highlight the need to incorporate partners into the psychosocial support provided to women facing BC. This can be done by adopting couple-based interventions or, at least, offer support to partners of women with BC, since there is still scarce evidence that intervening with couples might be better than with patients ${ }^{72}$ Also, by identifying associations between some specific demographic, disease-related, and psychosocial factors and marital adjustment in the context of BC, this review allows the identification of women or couples that are at greater risk for marital distress and should be referred to psychological support according to their specific needs from diagnosis to survivorship.

\section{References}

1. Ferlay J, Steliarova-Foucher E, Lortet-Tieulent J, et al. Cancer incidence and mortality patterns in Europe: estimates for 40 countries in 2012. Eur J Cancer. 2013;49(6):1374-1403. doi:10.1016/j.ejca.2012.12.027.

2. $\quad$ Kayser K, Scott JL. Helping Couples Cope with Women's Cancers: An Evidence-Based Approach for Practitioners. Springer Science Business Media; 2008.

3. Baider L, Ever-Hadani P, Goldzweig G, Wygoda MR, Peretz T. Is perceived family support a relevant variable in psychological distress? J Psychosom Res. 2003;55(5):453-460. doi:10.1016/S0022-3999(03)00502-6.

4. Maunsell E, Guay S, Yandoma É, et al. Patterns of confidant use among patients and spouses in the year after breast cancer. J Cancer Surviv. 2009;3(4):202-211. doi:10.1007/s11764-0090096-z.

5. Ávila, M; Brandão, T; Coimbra, J L; Lopez, F; Matos PM. Experiencing an intimate partner's breast cancer: Attachment, caregiving and burden in men. PSYCHIATRY Interpers Biol Process. 2016.

6. Badger T, Segrin C, Dorros SM, Meek P, Lopez AM. Depression and anxiety in women with breast cancer and their partners. Nurs Res. 2007;56(1):44-53. http://www.ncbi.nlm.nih.gov/pubmed/17179873.

7. Montazeri A, Vahdaninia M, Harirchi I, Ebrahimi M, Khaleghi F, Jarvandi S. Quality of life in patients with breast cancer before and after diagnosis: An eighteen months follow-up study. BMC Cancer. 2008;8(1):330. doi:10.1186/1471-2407-8-330.

8. Moreira H, Canavarro MC. A longitudinal study about the body image and psychosocial 
adjustment of breast cancer patients during the course of the disease. Eur J Oncol Nurs. 2010;14(4):263-270. doi:10.1016/j.ejon.2010.04.001.

9. Moreira H, Canavarro MC. Psychosocial adjustment and marital intimacy among partners of patients with breast cancer: a comparison study with partners of healthy women. J Psychosoc Oncol. 2013;31(3):282-304. doi:10.1080/07347332.2013.778934.

10. Wagner CD, Bigatti SM, Storniolo AM. Quality of life of husbands of women with breast cancer. Psychooncology. 2006;15(2):109-120. doi:10.1002/pon.928.

11. VandenBos GR, American Psychological Association. APA Dictionary of Psychology. American Psychological Association; 2007.

12. Heyman RE, Sayers SL, Bellack AS. Global marital satisfaction versus marital adjustment: An empirical comparison of three measures. J Fam Psychol. 1994;8(4):432-446. http://psycnet.apa.org/index.cfm?fa=buy.optionToBuy\&id=1995-07969-001. Accessed December 13, 2016.

13. Proulx CM, Helms HM, Buehler C. Marital quality and personal well-being: A metaanalysis. J Marriage Fam. 2007;69(3):576-593. doi:10.1111/j.1741-3737.2007.00393.x.

14. Robles TF, Slatcher RB, Trombello JM, McGinn MM. Marital quality and health: A metaanalytic review. Psychol Bull. 2014;140(1):140-187. doi:10.1037/a0031859.

15. Martins M V., Costa P, Peterson BD, Costa ME, Schmidt L. Marital stability and repartnering: Infertility-related stress trajectories of unsuccessful fertility treatment. Fertil Steril. 2014;102(6):1716-1722. doi:10.1016/j.fertnstert.2014.09.007.

16. Ashmore JA, Emery CF, Hauck ER, MacIntyre NR. Marital adjustment among patients with chronic obstructive pulmonary disease who are participating in pulmonary rehabilitation. Hear Lung. 2005;34(4):270-278. doi:10.1016/j.hrtlng.2004.12.005.

17. Tavallaii SA, Nemati E, Khoddami Vishteh HR, Azizabadi Farahani M, Moghani Lankarani M, Assari S. Marital adjustment in patients on long-term hemodialysis: A case-control study. Iran J Kidney Dis. 2009;3(3):156-161. http://www.ncbi.nlm.nih.gov/pubmed/19617665. Accessed December 13, 2016.

18. Manne S, Ostroff J, Rini C, Fox K, Goldstein L, Grana G. The interpersonal process model of intimacy: the role of self-disclosure, partner disclosure, and partner responsiveness in interactions between breast cancer patients and their partners. J Fam Psychol. 
2004;18(4):589-599. doi:10.1037/0893-3200.18.4.589.

19. Speer JJ, Hillenberg B, Sugrue DP, et al. Study of sexual functioning determinants in breast cancer survivors. Breast J. 2005;11(6):440-447. doi:10.1111/j.1075-122X.2005.00131.x.

20. Weihs K, Enright T, Howe G, Simmens SJ. Marital satisfaction and emotional adjustment after breast cancer. J Psychosoc Oncol. 1999;17(1):33-49. doi:10.1300/J077v17n01_03.

21. Zimmermann T, Scott JL, Heinrichs N. Individual and dyadic predictors of body image in women with breast cancer. Psychooncology. 2009;19(10):1061-1068. doi:10.1002/pon.1660.

22. Yang H-C, Schuler T a. Marital quality and survivorship: slowed recovery for breast cancer patients in distressed relationships. Cancer. 2009;115(1):217-228. doi:10.1002/cncr.23964.

23. Baucom DH, Kirby JS, Pukay-Martin ND, et al. Men's psychological functioning in the context of women's breast cancer. J Marital Fam Ther. 2012;38(2):317-329. doi:10.1111/j.1752-0606.2009.00133.x.

24. Northouse L, Templin T, Mood D. Couples' adjustment to breast disease during the first year following diagnosis. J Behav Med. 2001;24(2):115-136.

http://www.ncbi.nlm.nih.gov/pubmed/11392915. Accessed December 13, 2016.

25. Segrin C, Badger T, Sieger A, Meek P, Lopez AM. Interpersonal well-being and mental health among male partners o women with breast cancer. Issues Ment Health Nurs. 2006;27(4):371-389. doi:10.1080/01612840600569641.

26. Dorval M, Guay S, Mondor M, et al. Couples who get closer after breast cancer: frequency and predictors in a prospective investigation. J Clin Oncol. 2005;23(15):3588-3596. doi:10.1200/JCO.2005.01.628.

27. Drabe N, Wittmann L, Zwahlen D, Büchi S, Jenewein J. Changes in close relationships between cancer patients and their partners. Psychooncology. 2013;22(6):1344-1352. doi:10.1002/pon.3144.

28. Moreira H, Crespo C, Pereira M, Canavarro MC. Marital quality among women with breast cancer: The role of marital intimacy and quality of life. Psicooncología. 2010;7(1):61-80.

29. Brandão T, Schulz MS, Matos PM. Psychological intervention with couples coping with breast cancer: A systematic review. Psychol Health. 2014;29(5):491-516. doi:10.1080/08870446.2013.859257. 
30. Keesing S, Rosenwax L, McNamara B. A dyadic approach to understanding the impact of breast cancer on relationships between partners during early survivorship. BMC Womens Health. 2016;16(1):57. doi:10.1186/s12905-016-0337-z.

31. Moher D, Liberati A, Tetzlaff J, Altman DG, PRISMA Group. Preferred reporting items for systematic reviews and meta-analyses: The PRISMA statement. Ann Intern Med. 2009;151(4):264-269. http://www.ncbi.nlm.nih.gov/pubmed/19622511. Accessed December $13,2016$.

32. von Elm E, Altman DG, Egger M, Pocock SJ, Gøtzsche PC, Vandenbroucke JP. The Strengthening the Reporting of Observational Studies in Epidemiology (STROBE) statement: Guidelines for reporting observational studies. Lancet. 2007;370(9596):14531457. doi:10.1016/S0140-6736(07)61602-X.

33. Badr H, Carmack CL, Kashy DA, Cristofanilli M, Revenson TA. Dyadic coping in metastatic breast cancer. Heal Psychol. 2010;29(2):169-180. doi:10.1037/a0018165.

34. Ming VMW. Psychological predictors of marital adjustment in breast cancer patients. Psychol Health Med. 2002;7(1):37-51. doi:10.1080/13548500120101540.

35. Kinsinger SW, Laurenceau J-P, Carver CS, Antoni MH. Perceived partner support and psychosexual adjustment to breast cancer. Psychol Health. 2011;26(12):1571-1588. doi:10.1080/08870446.2010.533771.

36. Rock EE, Steiner JL, Rand KL, Bigatti SM. Dyadic influence of hope and optimism on patient marital satisfaction among couples with advanced breast cancer. Support Care Cancer. 2014;22(9):2351-2359. doi:10.1007/s00520-014-2209-0.

37. Rottmann N, Hansen DG, Larsen PV, et al. Dyadic coping within couples dealing with breast cancer: A longitudinal, population-based study. Heal Psychol. 2015;34(5):486-495. doi: $10.1037 /$ hea0000218.

38. Donovan-Kicken E, Caughlin JP. A multiple goals perspective on topic avoidance and relationship satisfaction in the context of breast cancer. Commun Monogr. 2010;77(2):231256. doi:10.1080/03637751003758219.

39. Hinnen C, Hagedoorn M, Ranchor A V., Sanderman R. Relationship satisfaction in women: A longitudinal case-control study about the role of breast cancer, personal assertiveness, and partners' relationship-focused coping. Br J Health Psychol. 2008;13(4):737-754. 
doi:10.1348/135910707X252431.

40. Hodgson JH, Shields CG, Rousseau SL. Disengaging communication in later-life couples coping with breast cancer. Fam Syst Heal. 2003;21:145-163.

http://psycnet.apa.org/index.cfm?fa=buy.optionToBuy\&id=2003-99888-004. Accessed December 13, 2016.

41. Manne SL, Ostroff JS, Norton TR, Fox K, Goldstein L, Grana G. Cancer-related relationship communication in couples coping with early stage breast cancer. Psychooncology. 2006;15(3):234-247. doi:10.1002/pon.941.

42. Wimberly SR, Carver CS, Laurenceau J-P, Harris SD, Antoni MH. Perceived partner reactions to diagnosis and treatment of breast cancer: Impact on psychosocial and psychosexual adjustment. J Consult Clin Psychol. 2005;73(2):300-311. doi:10.1037/0022006X.73.2.300.

43. Pasipanodya EC, Parrish BP, Laurenceau J-P, et al. Social constraints on disclosure predict daily well-being in couples coping with early-stage breast cancer. J Fam Psychol. 2012;26(4):661-667. doi:10.1037/a0028655.

44. Moreira H, Crespo C, Pereira M, Canavarro MC. Marital quality among women with breast cancer: The role of marital intimacy and quality of life. Psicooncología. 2010;7(1):61-80.

45. Lewis FM, Hammond MA, Woods NF. The family's functioning with newly diagnosed breast cancer in the mother: The development of an explanatory model. J Behav Med. 1993;16(4):351-370. http://www.ncbi.nlm.nih.gov/pubmed/8411142. Accessed December 13, 2016.

46. Manne SL, Ostroff JS, Norton TR, Fox K, Grana G, Goldstein L. Cancer-specific selfefficacy and psychosocial and functional adaptation to early stage breast cancer. Ann Behav Med. 2006;31(2):145-154. doi:10.1207/s15324796abm3102_6.

47. Woloski-Wruble AC, Dekeyzer Ganz F, Jiang Y, Qiang W-M, Kadmon I. Israeli and Chinese partners of women with breast cancer: A cross-cultural view of marital issues. Psychooncology. 2012;21(3):324-331. doi:10.1002/pon.1899.

48. Spanier GB. Measuring dyadic adjustment: New scales for assessing the quality of arriage and similar dyads. J Marriage Fam. 1976;38(1):15. doi:10.2307/350547.

49. Huston TL, Vangelisti AL. Socioemotional behavior and satisfaction in marital relationships: 
A longitudinal study. J Pers Soc Psychol. 1991;61(5):721-733.

http://www.ncbi.nlm.nih.gov/pubmed/1753328. Accessed December 13, 2016.

50. Arrindell WA, Schaap C. The Maudsley Marital Questionnaire (MMQ): An extension of its construct validity. Br J Psychiatry. 1985;147:295-299. http://www.ncbi.nlm.nih.gov/pubmed/4063595. Accessed December 13, 2016.

51. Locke HJ, Wallace KM. Short marital-adjustment and prediction tests: Their reliability and validity. Marriage Fam Living. 1959;21(3):251. doi:10.2307/348022.

52. Traa MJ, De Vries J, Bodenmann G, Den Oudsten BL. Dyadic coping and relationship functioning in couples coping with cancer: A systematic review. Br J Health Psychol. 2014:1-39. doi:10.1111/bjhp.12094.

53. Tao P, Coates R, Maycock B. Investigating marital relationship in infertility: A systematic review of quantitative studies. J Reprod Infertil. 2012;13(2):71-80. http://www.ncbi.nlm.nih.gov/pubmed/23926528. Accessed December 14, 2016.

54. Bodenmann G, Pihet S, Kayser K. The relationship between dyadic coping and marital quality: A 2-year longitudinal study. J Fam Psychol. 2006;20(3):485-493. doi:10.1037/08933200.20.3.485.

55. Umberson D, Williams K, Powers DA, Liu H, Needham B. You make me sick: Marital quality and health over the life course. J Health Soc Behav. 2006;47(1):1-16. doi: $10.2307 / 30040295$.

56. Levenson RW, Carstensen LL, Gottman JM. Long-Term Marriage : Age , Gender , and Satisfaction. Psychol Aging. 1993;8(2).

57. Mosher CE, Danoff-Burg S. A review of age differences in psychological adjustment to breast cancer. J Psychosoc Oncol. 2005;23(2-3):101-114. http://www.ncbi.nlm.nih.gov/pubmed/16492654. Accessed December 13, 2016.

58. Gabriel CA, Domchek SM. Breast cancer in young women. Breast Cancer Res. 2010;12(5):212. doi:10.1186/bcr2647.

59. Litzinger S, Gordon KC. Exploring relationships among communication, sexual satisfaction, and marital satisfaction. J Sex Marital Ther. 2005;31(5):409-424. doi:10.1080/00926230591006719. 
60. Rehman US, Holtzworth-Munroe A. A cross-cultural examination of the relation of marital communication behavior to marital satisfaction. J Fam Psychol. 2007;21(4):759-763. doi:10.1037/0893-3200.21.4.759.

61. Picard L. Social issues: Marital support. In: M C, Picard MJ, eds. Adjuvant Therapy for Breast Cancer. New York: Springer: Springer US; 2009:441-450. doi:10.1007/978-0-38775115-3_26.

62. Regan TW, Lambert SD, Kelly B, et al. Cross-sectional relationships between dyadic coping and anxiety, depression, and relationship satisfaction for patients with prostate cancer and their spouses. Patient Educ Couns. 2014;96(1):120-127. doi:10.1016/j.pec.2014.04.010.

63. Bodenmann G. Dyadic coping and the significance of this concept for prevention and therapy. Zeitschrift für Gesundheitspsychologie. 2008;16(3):108-111. doi:10.1026/09438149.16.3.108.

64. LAWRENCE E, BUNDE M, BARRY RA, et al. Partner support and marital satisfaction: Support amount, adequacy, provision, and solicitation. Pers Relatsh. 2008;15(4):445-463. doi:10.1111/j.1475-6811.2008.00209.x.

65. Malik SH, Coulson N. The male experience of infertility: A thematic analysis of an online infertility support group bulletin board. J Reprod Infant Psychol. 2008;26(1):18-30. doi:10.1080/02646830701759777.

66. Graham JM, Diebels KJ, Barnow ZB. The reliability of relationship satisfaction: A reliability generalization meta-analysis. J Fam Psychol. 2011;25(1):39-48. doi:10.1037/a0022441.

67. Cook W, Kenny D. The Actor-Partner Interdependence Model: A model of bidirectional effects in developmental studies. Int J Behav Dev. 2005;29(2):101-109. doi:10.1080/01650250444000405.

68. Classen CC, Kraemer HC, Blasey C, et al. Supportive-expressive group therapy for primary breast cancer patients: a randomized prospective multicenter trial. Psychooncology. 2008;17(5):438-447. doi:10.1002/pon.1280.

69. Schmidt L, Holstein B, Christensen U, Boivin J. Does infertility cause marital benefit? Patient Educ Couns. 2005;59(3):244-251. doi:10.1016/j.pec.2005.07.015.

70. Keefe FJ, Caldwell DS, Baucom D, et al. Spouse-assisted coping skills training in the management of knee pain in osteoarthritis: Long-term followup results. Arthritis Care Res 
(Hoboken). 1999;12(2):101-111. http://www.ncbi.nlm.nih.gov/pubmed/10513498. Accessed December 13, 2016.

71. Regan TW, Lambert SD, Girgis A, Kelly B, Kayser K, Turner J. Do couple-based interventions make a difference for couples affected by cancer? A systematic review. $B M C$ Cancer. 2012;12(1):279. doi:10.1186/1471-2407-12-279.

72. Regan TW, Lambert SD, Girgis A, Kelly B, Kayser K, Turner J. Do couple-based interventions make a difference for couples affected by cancer?: A systematic review. $B M C$ Cancer. 2012;12(1):279. doi:10.1186/1471-2407-12-279. 
Table 1

Factors Associated with Marital Adjustment for Patients $(N=14)$.

\begin{tabular}{|c|c|c|c|}
\hline & \multicolumn{3}{|c|}{ Marital adjustment } \\
\hline & Positive association & Negative association & No association \\
\hline \multicolumn{4}{|c|}{ Sociodemographic variables } \\
\hline Age (older) & $\begin{array}{c}\text { Rock et al. } 2014 \\
\text { Rottmann et al. } 2015\end{array}$ & & Ming et al. 2012 \\
\hline Years of marriage & & & $\begin{array}{l}\text { Badr et al., } 2010 \\
\text { Ming et al. } 2012\end{array}$ \\
\hline Socioeconomic status & & & Lewis et al. 1993 \\
\hline Family income & & & Ming et al. 2012 \\
\hline Partner's age & & & Ming et al. 2012 \\
\hline Education & & & Rottmann et al. 2015 \\
\hline \multicolumn{4}{|c|}{ Disease-related variables } \\
\hline Physical impairment & & & Manne et al. 2006 \\
\hline $\begin{array}{l}\text { Years after } \\
\text { mastectomy }\end{array}$ & & & Ming et al. 2012 \\
\hline Comorbidity & & 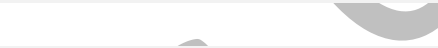 & Rottmann et al. 2015 \\
\hline Chemotherapy & & & Rottmann et al. 2015 \\
\hline Affected lymph nodes & & & Rottmann et al. 2015 \\
\hline Surgery & & & Rottmann et al. 2015 \\
\hline \multicolumn{4}{|l|}{ Psychosocial variables } \\
\hline \multicolumn{4}{|l|}{$\begin{array}{l}\text { Communication } \\
\text { patterns }\end{array}$} \\
\hline $\begin{array}{l}\text { Withdrawal, } \\
\text { protective buffering, } \\
\text { topic avoidance, } \\
\text { disengagement }\end{array}$ & & $\begin{array}{c}\text { Donovan-Kicken et al. } 2010 \\
\text { Hinnen et al. } 2008 \\
\text { Hodgson et al. } 2003\end{array}$ & \\
\hline $\begin{array}{c}\text { Constructive } \\
\text { communication and } \\
\text { disclosure of opinions }\end{array}$ & $\begin{array}{l}\text { Hinnen et al. } 2008 \\
\text { Manne et al. } 2006\end{array}$ & & \\
\hline Mutual avoidance & 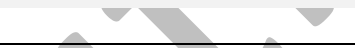 & & Manne et al. 2006 \\
\hline \multicolumn{4}{|l|}{ Social support } \\
\hline $\begin{array}{l}\text { Positive, emotional, } \\
\text { involvement social } \\
\text { support }\end{array}$ & Kinsinger et al. 2011 & & $\begin{array}{l}\text { Lewis et al. } 1993 \\
\text { Moreira et al. } 2010\end{array}$ \\
\hline $\begin{array}{c}\text { Negative social } \\
\text { support }\end{array}$ & & Wimberly et al. 2005 & \\
\hline $\begin{array}{l}\text { Patient constrain (i.e., } \\
\text { partner's avoidance or } \\
\text { disinterest related to } \\
\text { her cancer-related } \\
\text { concerns) }\end{array}$ & & Pasipanodya et al. 2012 & \\
\hline $\begin{array}{l}\text { Partner constrain (i.e., } \\
\text { partner perception of } \\
\text { own avoidance or } \\
\text { disinterest) }\end{array}$ & & & Pasipanodya et al. 2012 \\
\hline \multicolumn{4}{|l|}{$\begin{array}{l}\text { Psychological } \\
\text { adjustment }\end{array}$} \\
\hline Depression & & Lewis et al. 1993 & \\
\hline Quality of life & Moreira et al. 2010 & & \\
\hline Psychological distress & & & $\begin{array}{l}\text { Rock et al. } 2014 \\
\text { Ming et al. } 2012\end{array}$ \\
\hline Dyadic coping & & & \\
\hline
\end{tabular}


Common, positive dyadic coping

Rottmann et al. 2015

Supportive or

delegated dyadic coping

Negative dyadic

coping

Rottmann et al. 2015

Other variables

Sexual functioning

Self-efficacy

Hope patient

Hope partner

Optimism patient

Optimism partner

Empathy patient

Empathy partner

Body image patient

Body image (partner

perception)

Intimacy

Illness demands

\author{
Wimberly et al. 2005 \\ Manne et al. 2006 \\ Rock et al. 2014
}

Ming et al. 2012
Rock et al. 2014

Rock et al. 2014

Rock et al. 2014

Ming et al. 2012

Ming et al. 2012

Ming et al. 2012 
Table 2

Factors Associated with Marital Adjustment for Partners $(N=14)$.

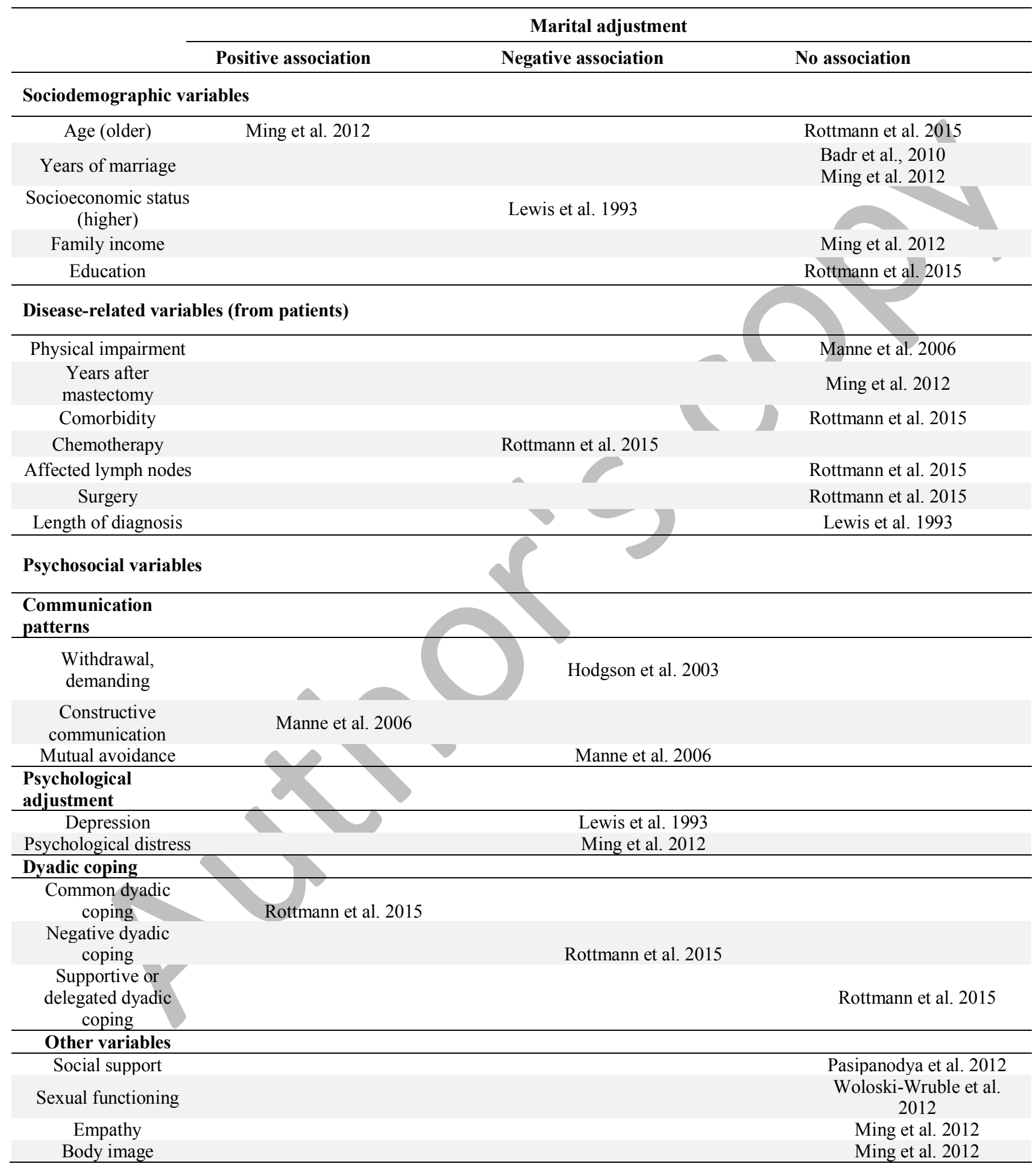

